\title{
Editorial
}

\section{AJET in 2021: Change, bibliometrics and future directions}

\author{
Kate Thompson \\ Queensland University of Technology, Australia
}

\author{
Linda Corrin \\ Swinburne University of Technology, Australia \\ Gwo-Jen Hwang \\ National Taiwan University of Science and Technology, Taiwan
}

\section{Jason M. Lodge}

The University of Queensland, Australia

\begin{abstract}
This is the first issue of AJET for 2021 and the first for the new Lead Editors. We introduce ourselves and celebrate the contributions of the outgoing team. In this editorial, we then present the AJET bibliometric data updated for 2020 and describe the changes to the team of Associate Editors that support the work of this journal. Finally we outline the articles that are included in this issue and present our plans for 2021 and into the future.
\end{abstract}

Keywords: bibliometric data, COVID-19, educational technology, higher education

\section{Introduction}

2020 was a year of significant change. Many education institutions worldwide were required to make changes to learning environments so that teaching and learning could continue throughout the COVID-19 pandemic. Educational technologies played a crucial role in enabling this change and the outcomes of research into ways that technology can be used effectively to support student learning became more important than ever before. In this context, AJET continued to offer open access to existing research, as well as publishing new research that could be used by educators to navigate these extraordinary circumstances.

AJET also experienced change at the end of 2020 as the team of Lead Editors decided to step down to explore other aspects of their academic careers. A competitive call and selection process resulted in the appointment of a new team of AJET Lead Editors. As members of this incoming team, we are very proud to be writing this, our first editorial for AJET, and the first for 2021. We understand there are many members of the AJET community who we have yet to meet. We are looking forward to this part of our roles and wanted to provide you with a brief introduction.

Associate Professor Linda Corrin is the Director, Learning Transformations Unit and Associate Professor, Learning Analytics at Swinburne University of Technology in Australia. Professor Gwo-Jen Hwang is the Chair Professor, Graduate Institute of Digital Learning and Education at the National Taiwan University of Science and Technology in Taiwan. Jason Lodge is an Associate Professor across the School of Education as well as the Institute for Teaching and Learning Innovation at the University of Queensland in Australia. Kate Thompson is the Associate Professor of Digital Pedagogies in the Faculty of Creative Industries, Education and Social Justice and also the Research Engagement Leader for Viser: Visualisation and Interactive Solutions for Engagement and Research at Queensland University of Technology in Australia.

The outgoing team has passed along a very successful journal that performs well on all the key metrics that indicate the quality of an academic journal. They have nurtured a journal that is a core part of the identity of the educational technology community in higher education in Australasia. We understand the responsibility we have to continue to support high quality research in the region and the translation of that research to practice for our readers. The outgoing team have also left us with a model of collaboration that is both productive and convivial, that we intend to continue. In this editorial, we will acknowledge the considerable work of the outgoing Lead Editorial team before discussing the bibliometric information about 
the journal for 2020. This will be followed by a description of the work of our associate editors and copy editors, before we conclude with a brief discussion of future directions for the journal.

\section{The outgoing editorial team}

We thank the outgoing team for what they have achieved over the past six years. Professor Michael Henderson began with AJET as an Associate Editor in 2012 and became a Lead Editor in 2014. Associate Professor Eva Heinrich joined the journal as Associate Editor in 2013 and became a Lead Editor in 2016. Associate Professor Petrea Redmond joined the journal as Associate Editor in 2015 and subsequently joined Michael and Eva as a Lead Editor in 2017. As Lead Editors they oversaw the day to day operation and strategic direction of the journal. After a combined service of 13 years as Lead Editors they stepped down at the end of 2020 .

The role of an AJET Lead Editor is very hands-on. The team meets each week to report on each of their various portfolios of work - from screening to publication - as well as to discuss and enact strategic decisions. Since 2015, as the outgoing team was forming, there has been immense growth in the work of the journal. Submissions increased by $65 \%$ to over 700 articles per year and as a consequence the team of Associate Editors has more than doubled. Despite this, the rigour of the journal review process has increased (acceptance rates halved to 8\%) while maintaining the timeliness of the process of decision-making (for example, authors can expect the desktop review stage to take less than seven days). In that time, the team of Editors reviewed approximately 3000 submissions, published approximately 350 papers, have written 26 editorials and published ten special issues. In total these articles and editorials have been downloaded 348,000 times with monthly abstract views almost trebling over the past five years. This is all due to the hard work of a very large and highly expert team of Editors (Lead, Associate and Copy).

The outgoing team of Lead Editors have shepherded a number of flagship projects to improve access, responsiveness and impact. During the last five years, the publication landscape has undergone significant change. The outgoing team has implemented strategies including the shift to early release to dramatically reduce the time between submission and publication. The move to creative commons licensing gave further clarity to the team's commitment to open access publishing. They brought in structured abstracts, upgraded journal software, and refined the process involved in editing AJET. The bibliometrics have strengthened across most systems. We appreciate that the impact of many of the strategies implemented will be felt in the years to come.

\section{Bibliometric data - what happened in 2020?}

The inclusion of bibliometric data in this editorial provides readers with information about the journal's publication, review and article access statistics, the articles attracting the most interest over the past year and the citation performance of the journal. The data has been summarised in a series of tables along with explanatory notes and brief commentary.

As can be seen in Table 1, AJET published 6 issues in 2020, including two special topic issues. Due to the increasing number of articles ready for publication AJET has continued to publish up to 12 articles per issue as well as making articles available on the website in early release format.

Table 1

AJET Publication Summary

\begin{tabular}{lrrrr}
\hline & 2017 & 2018 & 2019 & 2020 \\
\hline Issues published & 6 & 6 & 6 & 6 \\
Articles published & 57 & 57 & 63 & 59 \\
Editorials published & 6 & 6 & 6 & 6 \\
\hline
\end{tabular}

Table 2 shows the access numbers for the article landing pages (which display the article abstracts) and full article downloads per calendar year across all articles published in AJET. There was a $29 \%$ increase in access to article abstracts between 2019 and 2020, with access to the full articles more than doubling in this time. 
Table 2

Readership interest in AJET

\begin{tabular}{lrrr} 
& 2018 & 2019 & 2020 \\
\hline Access numbers to article landing pages (abstracts) & n.a. ${ }^{*}$ & 323,328 & 416,427 \\
Access numbers to full articles & 135,169 & 156,809 & 315,129 \\
\hline
\end{tabular}

* No reliable numbers are available due to system change

Table 3 shows the most downloaded articles per issue published in 2020. While it is difficult to determine the impact of the articles most recently published in such a short period of time, it is interesting to note that the most popular articles in the second half of the year were editorials. This is a good indication that the topics the journal focuses on are of direct and timely relevance to readers.

Table 3

Top 2020 AJET Articles per Issue by Full Article Downloads to 18/02/2021

\begin{tabular}{|c|c|c|c|}
\hline Issue & Article & Authors & Downloads \\
\hline $\begin{array}{l}\text { Vol } 36, \\
\text { No } 1\end{array}$ & Micro-teaching 2.0: Technology as the classroom & S Ledger, J Fischetti & 1,306 \\
\hline $\begin{array}{l}\text { Vol } 36, \\
\text { No } 2\end{array}$ & $\begin{array}{l}\text { Assessing the digital competence of educators in } \\
\text { social studies: An analysis in initial teacher training } \\
\text { using the TPACK- } 21 \text { model }\end{array}$ & $\begin{array}{l}\text { D Miguel-Revilla, J } \\
\text { Martínez-Ferreira, } \mathrm{M} \\
\text { Sánchez-Agustí }\end{array}$ & 787 \\
\hline $\begin{array}{l}\text { Vol } 36, \\
\text { No } 3\end{array}$ & $\begin{array}{l}\text { Investigating synchronous and asynchronous class } \\
\text { attendance as predictors of academic success in } \\
\text { online education }\end{array}$ & J Nieuwoudt & 1,556 \\
\hline $\begin{array}{l}\text { Vol } 36, \\
\text { No } 4\end{array}$ & $\begin{array}{l}2020 \text { vision: What happens next in education } \\
\text { technology research in Australia }\end{array}$ & K Thompson, J Lodge & 1,090 \\
\hline $\begin{array}{l}\text { Vol } 36, \\
\text { No } 5\end{array}$ & $\begin{array}{l}\text { Partnerships for scaled online learning and the } \\
\text { unbundling of the traditional university }\end{array}$ & $\begin{array}{l}\text { H Huijser, R Fitzgerald, } \\
\text { G Salmon }\end{array}$ & 601 \\
\hline $\begin{array}{l}\text { Vol 36, } \\
\text { No } 6\end{array}$ & Learning Analytics: Pathways to Impact & $\begin{array}{l}\text { L Corrin, M Scheffel, D } \\
\text { Gašević }\end{array}$ & 354 \\
\hline
\end{tabular}

Table 4 shows a comparison of the number of submissions and acceptance rates for articles submitted over the last three years. The number of submissions has remained fairly consistent, although early indications from submissions this year show that this figure is likely to increase in 2021.

Table 4

AJET Submission and Review Statistics based on submissions per year

\begin{tabular}{lrrr}
\hline AJET Submissions and Reviews & 2018 & 2019 & 2020 \\
\hline Total submissions & 707 & 703 & 703 \\
$\begin{array}{l}\text { Declined at editorial screening (percentage of total } \\
\text { submissions) }\end{array}$ & $523(74 \%)$ & $565(80 \%)$ & $496(71 \%)$ \\
Peer reviewed (percentage of total submissions) & $184(26 \%)$ & $138(20 \%)$ & $207(29 \%)$ \\
Declined at peer review (percentage of peer reviewed) & $129(70 \%)$ & $89(64 \%)$ & $118^{*}$ \\
Accepted (percentage of peer reviewed) & $55(35 \%)$ & $49(36 \%)$ & $45^{*}$ \\
Declined (either at editorial screening or following & $652(92 \%)$ & $653(93 \%)$ & $49(7 \%)$ \\
peer review, percentage of total submissions) & $55(8 \%)$ & 4020 & \\
Accepted (percentage of total submissions) & &
\end{tabular}

* These are preliminary figures as 44 articles submitted in 2020 are still under review

Table 5 shows a summary of citation statistics from Thomson Reuters Web of Science, Social Science Citation Index (SSCI), Journal Citation Reports (JCR), and Google Scholar citation statistics. The journal continues to rise up the rankings, demonstrating the quality of the contributions made by our authors and the hard work of our editorial team and copyeditors. As the journal transitions to a new Lead Editor team 
the intent is to maintain this trajectory so that AJET continues to be recognised as one of the leading journals in educational technology internationally.

Table 5

AJET Bibliometrics based on calendar year

\begin{tabular}{llccc}
\hline AJET Bibliometrics & & 2017 & 2018 & 2019 \\
\hline JCR & JCR Impact Factor & 1.396 & 1.578 & 1.96 \\
& JCR 5-year Impact Factor & 1.818 & 1.860 & 2.08 \\
& JCR journal ranking in Education & $111 / 238$ & $110 / 243$ & $95 / 263$ \\
& category based on 5-year Impact Factor & $\mathrm{Q} 2$ & $\mathrm{Q} 2$ & $\mathrm{Q} 2$ \\
\hline Scimago & SJR Impact Factor & 0.721 & 0.721 & 0.91 \\
& SJR ranking in Education & $\mathrm{Q} 1$ & $\mathrm{Q} 1$ & $\mathrm{Q} 1$ \\
\hline Google Scholar & H5 index within Educational & 26 & 28 & 35 \\
& H5 ranking & & $20 / 20$ & $13 / 20$ \\
& Technology category & 1.40 & & \\
\hline \multirow{2}{*}{ Scopus } & CiteScore & $226 / 979$ & $155 / 1040$ & $138 / 1254$ \\
& Journal ranking in Education & $\mathrm{Q} 1$ & $\mathrm{Q} 1$ & $\mathrm{Q} 1$ \\
& & 1.071 & 1.092 & 1.56 \\
\hline
\end{tabular}

\section{The editorial team}

A huge thanks goes to AJET's Associate Editors for their high-quality editorial work that contributes strongly toward our excellent and highly regarded journal. The Associate Editors are highly experienced researchers who expertly shepherd articles through the review process and volunteer considerable time to the journal.

The work of an Associate Editor is critical to the functioning of our journal. We take great pride in our team and it is always sad to say farewell. Last year, three Associate Editors stepped down so that they could pursue other roles. We sincerely thank them for all they have done for the journal over their combined 16 years of service:

- $\quad$ Professor Lina Markauskaite, The University of Sydney, Australia (Associate Editor, 2012-2020)

- Associate Professor Paul Andrew Gruba, University of Melbourne, Australia (Associate Editor, 2016-2020)

- Dr Eamon Costello, The National Institute for Digital Learning, Dublin City University, Ireland (Associate Editor, 2018-2020).

In addition to the above, three of our Associate Editors (Corrin, Lodge and Thompson) have taken up new positions as Lead Editors. We are very pleased to welcome seven new associate editors to the team for 2021. In 2021 our team of Associate Editors are:

- Dr Thomas Chiu (new), The Chinese University of Hong Kong

- Dr Simon K. S. Cheung (new), The Open University of Hong Kong, Hong Kong

- Dr Thomas Cochrane, University of Melbourne, Australia

- Dr Christopher E Dann, University of Southern Queensland, Australia

- Associate Professor Teresa S Foulger, Arizona State University, United States

- Dr Feifei Han (new), Griffith University, Australia

- $\quad$ Professor Judi Harris, College of William \& Mary, USA

- Dr Henk Huijser, Queensland University of Technology, Australia

- Associate Professor Matthew Kearney, University of Technology Sydney, Australia

- Dr Chien-Ching Lee, Singapore Institute of Technology, Singapore

- Associate Professor Stephen Marshall, Victoria University of Wellington, New Zealand

- Associate Professor Michael Phillips, Monash University, Australia

- Dr Kwong Nui Sim (new), Auckland University of Technology, New Zealand

- Professor Jerry Chih-Yuan Sun (new), National Chiao Tung University, Taiwan

- Professor Joke Voogt, University of Amsterdam/Windesheim University of Applied Sciences, Netherlands 
- Associate Professor Haoran Xie, Lingnan University, Hong Kong

- Associate Professor Lanquin Zheng (new), Beijing Normal University, China

- Dr Di Zou (new), The Education University of Hong Kong, Hong Kong

We also thank the wonderful AJET Copyeditors Antonina Petrolito and Kayleen Wood who work closely with the Lead Editors and authors to ensure a high standard of final proofs is maintained. AJET is a large endeavour and the editors draw on the strategic insights of the Editorial Board and AJET Management Committee. In particular, we thank ASCILITE President, Dr Chris Campbell, and ASCILITE Treasurer, Dr Mark Schier who have provided unwavering support for the continued development of the journal.

\section{In this issue}

There are twelve articles in this issue that broach topics of interest to many people in the AJET community - including blended learning in undergraduate teaching (Keskitalo \& Ruokamo, 2021), the use of video to support collaboration in the Phillippines (Garcia Mendoza \& Jung, 2021) and the application of AR (Chin \& Wang, 2021) and VR (Schott \& Marshall, 2021) in tertiary education.

In the first article, Ellis, Bliuc and Han (2021) investigate the assessment of effective collaboration in blended learning environments in university courses in Australia. They used innovative combinations of methodologies to find patterns in the way students collaborate in a first year, undergraduate course and make recommendations for teacher practice. In the second article Keskitalo and Ruokamo (2021) use questionnaire data to identify emotions before and after simulation learning in Medical education in Lapland. They identified three student emotional profiles and used these to make recommendations for practice related to addressing the emotional profiles before, during and after student participation in simulations. In the third article, Chin and Wang (2021) report on an AR based mobile touring system of heritage sites in Taiwan for a cultural heritage unit. They investigated the impact on learning (memorising and integrating new knowledge) as well as interest in learning (actualised and task-based). Dalal, Archambault and Shelton (2021) are based in the USA and implemented training for teachers from developing nations about the use of TPACK to support the inclusion of technology into their practice. At the end of the article, they raise concerns about the implications of the challenges associated with access to technology for teachers and learners in developing countries in relation to teacher practice. In the fifth article, Garcia Mendoza and Jung (2021) explore the role of empathy in a collaborative immersive environment by comparing text and video based collaborative activities in a programming task. The sixth article (Song, 2021) reports on the implementation of e-portfolios as a tool to support students in their organisation, collaboration and learning. The focus of this study was on learners' perspectives on the use of the tool and the author makes recommendations for the use of e-portfolios within LMS's moving forward.

In the seventh article, Connolly et al. (2021) describe the combination of two frameworks to analyse an online platform (the Teachers' Research Exchange - T-REX - platform) to support teachers in the sharing of decision-making about technology and interpretation of research to inform their practice in Ireland. This paper adds to the widening literature on how technology can be used to connect educators in research approaches to their practice. Schott and Marshall (2021) adopt a UX lens to understand the ways in which VR can be used to support experiential education based on a Unity software-based virtual island in Fiji. This exploratory analysis of the user experience of teachers and students will be essential to inform further developments in the emerging area of VR in education. The ninth article focuses on the factors associated with attrition in an online law school in the Australian context (George, McEwan and Tarr, 2021). In particular, the authors were interested in how feelings of isolation had impacted the perceived strengths and challenges of online legal study. The authors provide recommendations for student wellbeing, course and unit design as well as policy and theory in relation to online learning. Donkin and Kynn (2021) investigate the intersection between space, collaboration and learning in the tenth article in this issue. By measuring grade outcomes as well as engagement and motivation they were able to inform guidelines for best practice of technology-enabled collaboration spaces. Ismael \& Al Mulhim's study (2021) combines work on visualisations with that on representations to understand the influence of different types of infographics on students' academic achievement with third-year undergraduates in Saudia Arabia. This study has implications for the use of visual representations for the communication of data. Finally, Evans, Kensington-Miller and Novka (2021) from the University of Auckland, examine pre-lecture quizzes and 
their impact on learners' engagement. They carried out their study using course transition space as their perspective for analysing the data as well as to design the unit. This study provides a framework to further investigate the impact of pedagogical practice on student learning.

\section{What comes next?}

As we release this first issue as the incoming team of Lead Editors, we are excited to share some of our future plans. We will begin by outlining the two special issues that will be featured in AJET this year followed by a discussion of how we view this changing technology landscape, as well as our vision for supporting and strengthening the AJET and ASCILITE communities going forward.

The first special issue topic (Issue 2) this year relates to smart learning environments. This issue will focus on emerging technologies, such as AR and VR, adaptive learning, game-based learning and intelligent tutoring systems. All indications are that this will be a bumper issue with many impactful papers on these cutting-edge technologies and environments. This first special issue for the year is being edited by Simon K.S. Cheung and Fu Lee Wang (both The Open University of Hong Kong), and Lam For Kwok (City University of Hong Kong). The second special issue will focus on 'emerging technologies in education for innovative pedagogies and competency development'. The call for papers for this issue is open now with submissions due April 1st, 2021. More details about this special issue are available on the AJET website. It is being edited by Asad Abbas and Samira Hosseini (both Tecnológico de Monterrey, Mexico) and José Luis Martín Núñez and Susana Sastre-Merion (both Universidad Politécnica de Madrid).

These special issues provide a foundation for the future direction of AJET. We are keen for the journal to be at the cutting edge of innovation and progress in relation to educational technology. This necessarily includes a focus on the use of a range of technologies such as virtual reality, augmented reality and mixed reality, as well as the development of educator capabilities to use these technologies effectively. It is most likely that applications based on approaches such as learning analytics or artificial intelligence (AI) will become more intrinsic to our practice in higher education. As universities increasingly invest in technology that bridges the digital/physical divide, the outcomes of opportunities for research on their impact on pedagogical practice and student and teacher learning will be crucial to inform a robust conversation about the ongoing role of technology in education. This is particularly important as the world continues to adapt to restrictions on physical interactions as a result of COVID-19, where the evidence-informed leadership of researchers and practitioners in this community will remain a critical role for journals such as AJET.

As an open access journal with an international focus, AJET is a conduit to connect researchers, practitioners and policymakers as part of a global community. The last year has provided dramatic evidence for the need for members of the community to work together towards enhancing student learning in higher education institutions around the world. As Lead Editors of AJET, we bear some responsibility for ensuring that this conduit remains open and that high quality interactions remain a core principle, which will benefit to both the ASCILITE and global educational technology in higher education communities. At the same time, this editorial demonstrates that AJET is very much a team effort. We are very grateful for the opportunity to serve as Lead Editors of the journal and for the support we have inherited from the great team of associate editors, the AJET copyeditors, the ASCILITE executive and, of course, our generous reviewers. We are relishing the opportunity to work with such a great team now and in the years to come.

Kate Thompson, Linda Corrin, Gwo-Jen Hwang, and Jason M. Lodge

Lead Editors Australasian Journal of Education Technology

\section{Acknowledgements}

A huge thanks goes to the associate editors for their high-quality editorial work that contributes strongly towards our excellent and highly regarded journal. The associate editors are highly experienced researchers who expertly shepherd papers through the review process and volunteer their time to the journal. We thank the AJET copyeditors who work closely with the Lead Editors to ensure a high standard of final proofs is maintained. We also extend heartfelt thanks to our international team of reviewers who perform an invaluable service to the journal. 


\section{References}

Chin, K.-Y., \& Wang, C.-S. (2021). Effects of augmented reality technology in a mobile touring system on university students' learning performance and interest. Australasian Journal of Educational Technology, 37(1), 27-42. https://doi.org/10.14742/ajet.5841

Connolly, C., Hall, T., Ryan, M., McMahon, J., McGann, M., \& Egan, A. (2021). A fusion of researchinformed teaching and teaching-informed research: Designing a scalable online ecosystem for new partnerships in educational research. Australasian Journal of Educational Technology, 37(1), 82-95. https://doi.org/10.14742/ajet.6131

Dalal, M., Archambault, L., \& Shelton, C. (2021). Fostering the growth of TPACK among international teachers of developing nations through a cultural exchange program. Australasian Journal of Educational Technology, 37(1), 43-56. https://doi.org/10.14742/ajet.5964

Donkin. R., \& Kynn, M. (2021). Does the learning space matter? An evaluation of active learning in a purpose-built technology-rich collaboration studio. Australasian Journal of Educational Technology, 37(1), 133-146. https://doi.org/10.14742/ajet.5872

Ellis, R., Bluic, A.-M., \& Han, F. (2021). Challenges in assessing the nature of effective collaboration in blended university courses. Australasian Journal of Educational Technology, 37(1), 1-14. https://doi.org/10.14742/ajet.5576

Evans, T., Kensingon-Miller, B., \& Novak, J. (2021). Effectiveness, efficiency, engagement: mapping the impact of pre-lecture quizzes on educational exchange. Australasian Journal of Educational Technology, 37(1), 163-177. https://doi.org/10.14742/ajet.6258

Garcia Mendoza, G. A., \& Jung, I. (2021). Understanding immersion in 2D platform-based online collaborative learning environments. Australasian Journal of Educational Technology, 37(1), 57-67. https://doi.org/10.14742/ajet.6106

George, A-J., McEwan, A., \& Tarr, J-A.. (2021). Accountability in educational dialogue on attrition rates: Understanding external attrition factors and isolation in online law school. Australasian Journal of Educational Technology, 37(1), 111-132. https://doi.org/10.14742/ajet.6175

Ismaeel, D. A., \& Al Mulhim E. N. (2021). The influence of interactive and static infographics on the academic achievement of reflective and impulsive students. Australasian Journal of Educational Technology, 37(1), 147-162. https://doi.org/10.14742/ajet.6138

Keskitalo, T., \& Ruokamo, H. (2021). Exploring learners' emotions and emotional profiles in simulationbased medical education. Australasian Journal of Educational Technology, 37(1), 15-26. https://doi.org/10.14742/ajet.5761

Schott, C., \& Marshall, S. (2021). Full-immersion virtual reality for experiential education: An exploratory user experience analysis. Australasian Journal of Educational Technology, 37(1), 96-110. https://doi.org/10.14742/ajet.5166

Song, B. K. (2021). E-portfolio implementation: Examining learners' perception of usefulness, selfdirected learning process and value of learning. Australasian Journal of Educational Technology, 37(1), 68-81. https://doi.org/10.14742/ajet.6126

Corresponding author: AJET Editors, editors@ ajet.org.au

Copyright: Articles published in the Australasian Journal of Educational Technology (AJET) are available under Creative Commons Attribution Non-Commercial No Derivatives Licence (CC BY-NC-ND 4.0). Authors retain copyright in their work and grant AJET right of first publication under CC BY-NC-ND 4.0.

Please cite as: Thompson, K., Corrin L., Hwang, G-J., \& Lodge, J. M. (2021). AJET Bibliometrics and developments. Australasian Journal of Educational Technology, 37(1), 1-7. https://doi.org/10.14742/ajet.7010 